\title{
Investigação sorológica das lentiviroses de pequenos ruminantes nas microrregiões homogêneas do Alto Médio Canindé, Picos e Floriano, Piauí, Brasil
}

\author{
Serological investigation of lentiviruses of small ruminants in the \\ microregions of Alto Médio Canindé, Picos and Floriano, Piauí state, Brazil
}

\author{
Ricardo Abílio Bezerra e Silva * , Maria do Carmo de Souza Batista', Raíssa Paula Araújo Alves ', \\ Francisco Selmo Fernandes Alves², Raymundo Rizaldo Pinheiro², Bruno Leandro Maranhão Diniz ${ }^{3}$, \\ Wagner Martins Fontes do Rêgo ${ }^{3}$, Janaina de Fátima Saraiva Cardoso ${ }^{1}$, Ney Rômulo de Oliveira Paula'
}

RESUMO: Lentivírus de pequenos ruminantes (LV) é o termo genérico utilizado para designar os vírus da artrite encefalite caprina e Maedi-Visna, os quais pertencem à família Retroviridae, subfamília Orthoretrovirinae, gênero Lentivirus. Tais vírus infectam caprinos e ovinos, causando enfermidades de curso lento com lesôes inflamatórias, crônicas e degenerativas que podem atingir vários órgãos, provocando caquexia e morte. Os animais infectados eliminam o vírus sobretudo por meio de secreçôes e excreçóes e transmitem-no especialmente em situaçóes de estreito contato. Não há tratamento até o momento. O controle é baseado na criação segregada, no manejo e no sacrifício dos positivos. Esse agente infeccioso já foi relatado em várias partes do mundo, sendo responsável por perdas econômicas significativas. Por o agente ter sido verificado em vários estados do Brasil e por não existirem dados soroepidemiológicos nas mesorregióes sudeste e sudoeste piauiense, esta pesquisa teve por objetivo realizar inquérito sorológico para investigar a ocorrência de anticorpos para o LV em ovinos e caprinos nas microrregiōes do Alto Médio Canindé, Picos e Floriano, no Piauí. Para tanto, foram coletadas 1.280 e 1.360 amostras de soro caprino e ovino, respectivamente, oriundos de 20 municípios, distribuídos nas três microrregióes, sendo o número de amostras proporcional ao rebanho efetivo de cada município. As amostras de soro foram analisadas utilizando o teste de imunodifusão em gel de agarose (IDGA). Nenhum dos soros pesquisados reagiu positivamente, constatando-se soroprevalência nula. Ressalta-se a importância da implantação de um rigoroso programa de controle para que se possa evitar a introduçáo e/ou a disseminação desse agente infeccioso nessas microrregiōes.

PALAVRAS-CHAVE: Lentivírus; artrite encefalite caprina; Maedi-Visna; imunodifusão em gel de ágar.

\begin{abstract}
Small ruminant lentiviruses (LV) is the generic term for the caprine arthritis-encephalitis and MaediVisna viruses, which belong to the Retroviridae family, Orthoretrovirinae subfamily, Lentivirus genus. The virus infects goats and sheep, causing slow course of disease with inflammatory, chronic and degenerative lesions, which can reach several organs, provoking cachexia and death. Infected animals eliminate the virus mainly through secretions and excretions and transmit it especially in close contact situations. There is no treatment to date. The control is based on segregated creation, management and sacrifice of the positive. This infectious agent has been reported in various parts of the world and is responsible for significant economic losses. It was verified in several states of Brazil and there are seroepidemiological data in southeast and southwest mesoregions of Piauí, Brazil. This research aimed to perform serological survey to investigate the occurrence of antibodies to LV in sheep and goats, in the regions of Alto Médio Canindé, Picos and Floriano. So, 1,280 and 1,360 serum goats and sheep samples, respectively, were collected, coming from 20 municipalities, distributed in the 3 microregions. The number of samples was proportional to the actual herd of each municipality. The samples were analyzed using the agar gel immunodiffusion test. None of the surveyed sera reacted positively, though there is a null seroprevalence. It was emphasized the importance of implementing a rigorous control program in order to prevent the introduction and spread of this infectious agent in these microregions.
\end{abstract}

KEYWORDS: Lentivirus; caprine arthritis encephalitis; MaediVisna; agar gel immunodiffusion test.

\footnotetext{
'Departamento de Morfofisiologia Veterinária, Universidade Federal do Piauí (UFPI) - Teresina (PI), Brasil.

${ }^{2}$ Centro Nacional de Pesquisa de Caprinos e Ovinos, Empresa Brasileira de Pesquisa Agropecuária (EMBRAPA Caprinos e Ovinos)/Centro Nacional de Pesquisas de Caprinos (CNPC) - Sobral (CE), Brasil.

${ }^{3}$ Departamento de Medicina Veterinária, UFPI - Bom Jesus (PI), Brasil.

*Autor correspondente: ricardoabilio@gmail.com

Recebido em: 20/04/2015. Aceito em: 05/10/2016
} 


\section{INTRODUÇÃO}

O termo lentivírus de pequenos ruminantes (LV) engloba os vírus da artrite encefalite caprina (CAEV) e Maedi-Visna (MVV), os quais infectam caprinos e ovinos, causando lesôes inflamatórias crônicas e degenerativas no cérebro, nos pulmões, nas articulaçóes e nas glândulas mamárias (NARAYAN; CLEMENTS, 1989).

Os LV são RNA-vírus pertencentes à família Retroviridae, subfamília Orthoretrovirinae, gênero Lentivirus (MURRAY et al., 2000). Correspondem a vários agentes que acometem animais vertebrados e são detentores de similaridade biológica e molecular. Estáo agrupados filogeneticamente em cinco grupos distintos, entre os quais estáo o CAEV e o MVV (SHAH et al., 2004).

Animais infectados eliminam o vírus principalmente por meio de secreçôes, que contêm células do sistema monociticofagocitário ricas em partículas virais (BLACKLAWS et al., 2004), transmitindo-o aos animais suscetíveis, especialmente em situações de estreito contato, como as observadas em sistemas de criação intensiva (PINHEIRO et al., 2004).

A infecção por LV em caprinos e ovinos já foi relatada em várias partes do mundo com perdas econômicas significativas, por vezes subestimadas (OIE, 2008). Os prejuízos resultam do comprometimento da produtividade, da desvalorizaçáo comercial dos animais e das despesas com programas de controle, que estáo baseados principalmente na segregaçáo e no abate dos animais soropositivos, uma vez que não existe tratamento nem vacina eficaz contra o LV (REINA et al., 2009; BLACKLAWS, 2012).

$\mathrm{Na}$ região nordeste, encontram-se registros sorológicos das lentiviroses de pequenos ruminantes (LVPR) em diversos estados: Bahia (MARTINEZ et al., 2010; LIMA et al., 2013), Ceará (PINHEIRO; GOUVEIA; ALVES, 2001), Maranhão (ALVES; PINHEIRO, 1997), Paraíba (BANDEIRA et al., 2008), Pernambuco (COSTA et al., 2007); Piauí (SAMPAIO JÚNIOR et al., 2011; DINIZ, 2011), Rio Grande do Norte (SILVA et al., 2005) e Sergipe (MELO et al., 2003).

O levantamento soroepidemiológico atualizado das LVPR constitui o primeiro passo a ser tomado para a implementaçáo de medidas profiláticas e de controle dessas enfermidades. Considerando-se a inexistência de informaçōes sobre os $\mathrm{LV}$ nas mesorregiōes sudeste e sudoeste do estado do Piauí, bem como a importância desse cinturão geográfico e agropecuário para as produçóes ovina e caprina piauiense, este trabalho foi desenvolvido com o objetivo de estimar a prevalência das LVPR nas microrregiōes do Alto Médio Canindé (MRAMC), Picos (MRP) e Floriano (MRF).

\section{MATERIAL E MÉTODOS}

A MRAMC (Fig. 1) está situada na mesorregiāo sudeste piauiense. Possui área territorial de $31.239,813 \mathrm{~km}^{2}$ distribuídos em 39 municípios e apresenta o maior rebanho efetivo caprino e ovino do estado, com 618.356 cabeças. Também pertencente à mesorregiâo sudeste piauiense, a MRP (Fig. 1), composta de 20 municípios com área territorial de $10.337,587 \mathrm{~km}^{2}$ e um rebanho de ovinos e caprinos da ordem de 96.466 cabeças. A MRF (Fig. 1), com rebanho estimado em 122.062 cabeças de pequenos ruminantes, pertence à mesorregiáo sudoeste piauiense, sendo formada por 12 municípios, que perfazem a área territorial de $18.333,419 \mathrm{~km}^{2}$ (IBGE, 2013).

O procedimento experimental foi aprovado pela Comissão de Ética e Experimentação no Uso de Animais em Pesquisa, da Universidade Federal do Piauí (UFPI), com número de protocolo 020/14. As amostras sanguíneas foram colhidas por puncionamento venoso jugular, após antissepsia local, com álcool iodado a $2 \%$, utilizando-se frascos descartáveis de colheita de sangue a vácuo, sem anticoagulante com ativador de coágulo. No momento da colheita foi preenchida uma ficha de campo com os dados da data da colheita, município, propriedade e proprietário, bem como a identificação individual dos animais (espécie, raça e idade). Após a identificação, as amostras foram refrigeradas e transportadas a um local de apoio, para que fosse possível centrifugá-las a $3.000 \mathrm{rpm}$ durante 15 minutos. As amostras de soro foram entâo acondicionadas em microtubos de $1,5 \mathrm{~mL}$, identificadas e congeladas a $-20^{\circ} \mathrm{C}$, até a realização das análises sorológicas.

Para detecçấo de anticorpos anti-LV, usou-se a técnica de imunodifusão em gel de ágar (IDGA), descrita por GOUVEIA et al. (2000) e recomendada pela Organização Mundial da Saúde Animal (OIE, 2008), mediante $30 \mu \mathrm{L}$ de antígeno (Ag) nacional, produzido no Laboratório de Virologia da Empresa Brasileira de Pesquisa Agropecuária (EMBRAPA) Caprinos e Ovinos, derivado de culturas celulares oriundas da membrana sinovial e inoculadas com cepa padrão CAEV-Cork contendo as proteínas totais do vírus. A leitura foi realizada após $48 \mathrm{e}$ 72 horas com auxílio de luz indireta e fundo escuro.

O número mínimo de amostras a serem colhidas foi calculado estatisticamente, considerando a prevalência estimada em 5\%, com erro amostral de $20 \%$ e grau de confiança de $95 \%$ (ASTUDILLO, 1979). A estimativa da prevalência levou em conta a média dos resultados observados em inquéritos sorológicos conduzidos em outros estados brasileiros.

O cálculo amostral identificou o número mínimo de amostras de soro caprino e ovino a ser colhido: 1.280 e 1.320, respectivamente. Entretanto, da espécie ovina, foram colhidas amostras de 1.360 animais. Dessa forma, participaram da pesquisa 64 (Fig. 2) rebanhos de caprinos e 68 de ovinos (Fig. 3), que foram selecionados por método não probabilístico, já que não havia listas de propriedades que possibilitassem a amostragem aleatória. $\mathrm{O}$ número de amostras por município foi proporcional à participação de cada um deles no rebanho total da microrregiáo a que pertence (Tabs. 1 e 2), de acordo com os dados do Instituto Brasileiro de Geografia e Estatística (IBGE) (BRASIL, 2009). Fizeram parte do processo de amostragem, de modo aleatório, 20 animais em cada propriedade, entre os quais: $60 \%$ de matrizes, $30 \%$ de jovens (entre 6 e 12 meses) e $10 \%$ de reprodutores adultos. 


\section{RESULTADOS E DISCUSSÃO}

Das 1.360 amostras de soro ovino e 1.280 amostras de soro caprino coletadas, nenhuma delas apresentou anticorpos anti-LV. Portanto, não houve associação significativa com os fatores de risco para infecção por LV. Esses resultados apontam soroprevalência nula das LVPR nos rebanhos das microrregióes pesquisadas.

Os sistemas de criação frequentemente encontrados nas microrregióes estudadas caracterizam-se pelo regime extensivo, no qual os animais ficam soltos em grandes áreas e o criador exerce pouco controle sobre eles, principalmente no aspecto reprodutivo. Esse perfil é comumente adotado na Região Nordeste do Brasil, onde os animais são criados com baixa ou nenhuma tecnologia (PINHEIRO et al., 2000) e se alimentam sobretudo de pastagem nativa, o que acarreta baixa produtividade e também alta morbidade, em virtude do manejo alimentar inadequado (SOUZA et al., 2007; GOUVEIA et al., 2009).

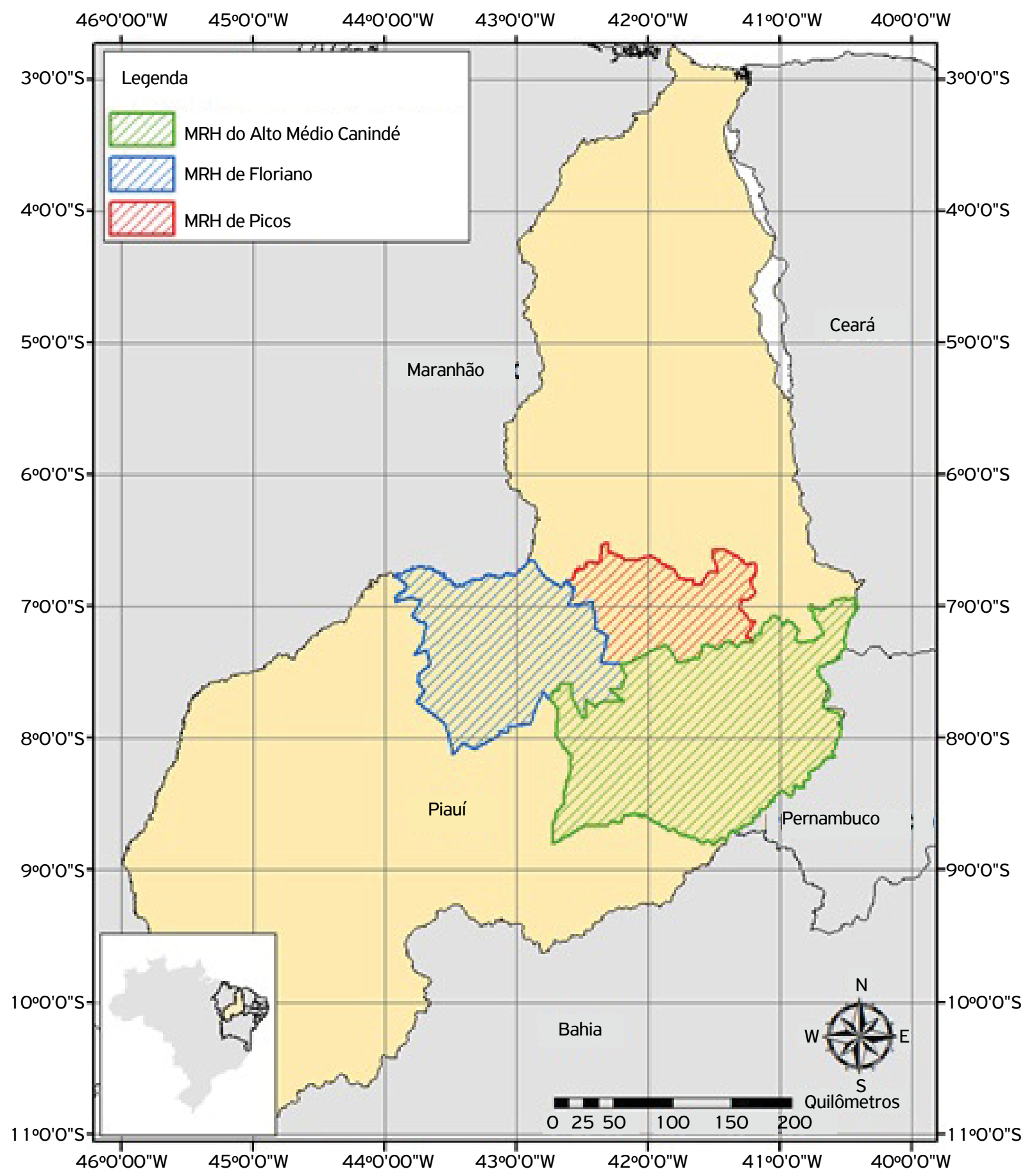

MRH: microrregião homogênea.

Figura 1. Microrregiões do Alto Médio Canindé, Picos e Floriano, Piauí, Brasil (BRASIL, 2013). 
O resultado obtido na espécie ovina foi semelhante ao obtido por SILVA (2011) em um estudo realizado na microrregião de Teresina, Piauí. Ali, em um universo amostral de 452 animais, também não foi possível encontrar ovinos soropositivos. Tal dado ainda se aproxima dos encontrados por DINIZ (2011) em rebanhos ovinos criados predominantemente de forma extensiva na regiáo sul piauiense, na qual apenas $0,5 \%$ dos animais se apresentaram sororreagentes ao LV.

Assim como nesta pesquisa, estudos soroepidemiológicos realizados nos estados do Ceará (PINHEIRO et al., 1996), Sergipe (MELO et al., 2003), Paraíba (GOUVEIA et al., 2003),

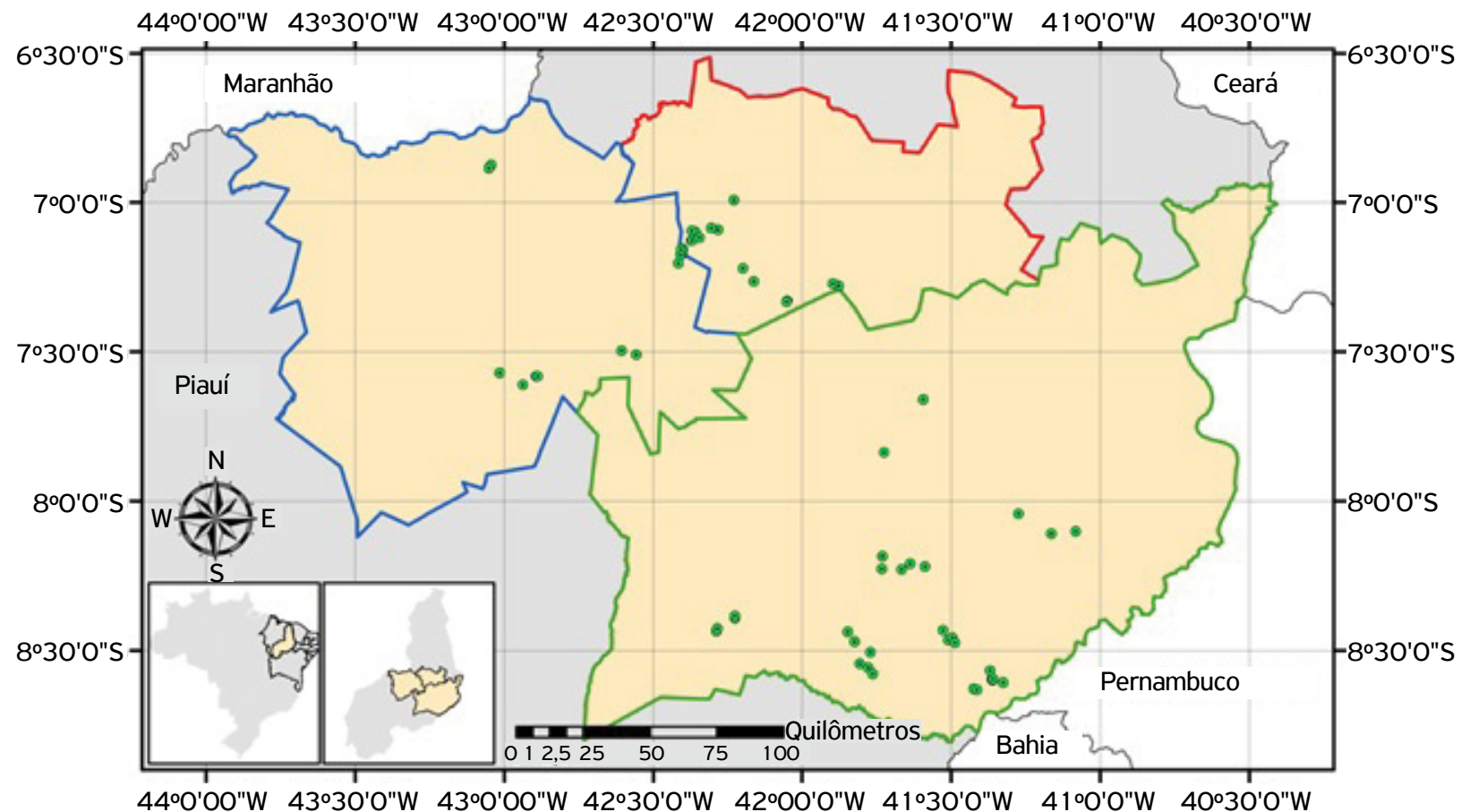

Figura 2. Localização georreferenciada das unidades produtoras de caprinos que participaram do estudo nas microrregiões do Alto Médio Canindé, Picos e Floriano, Piauí, Brasil.

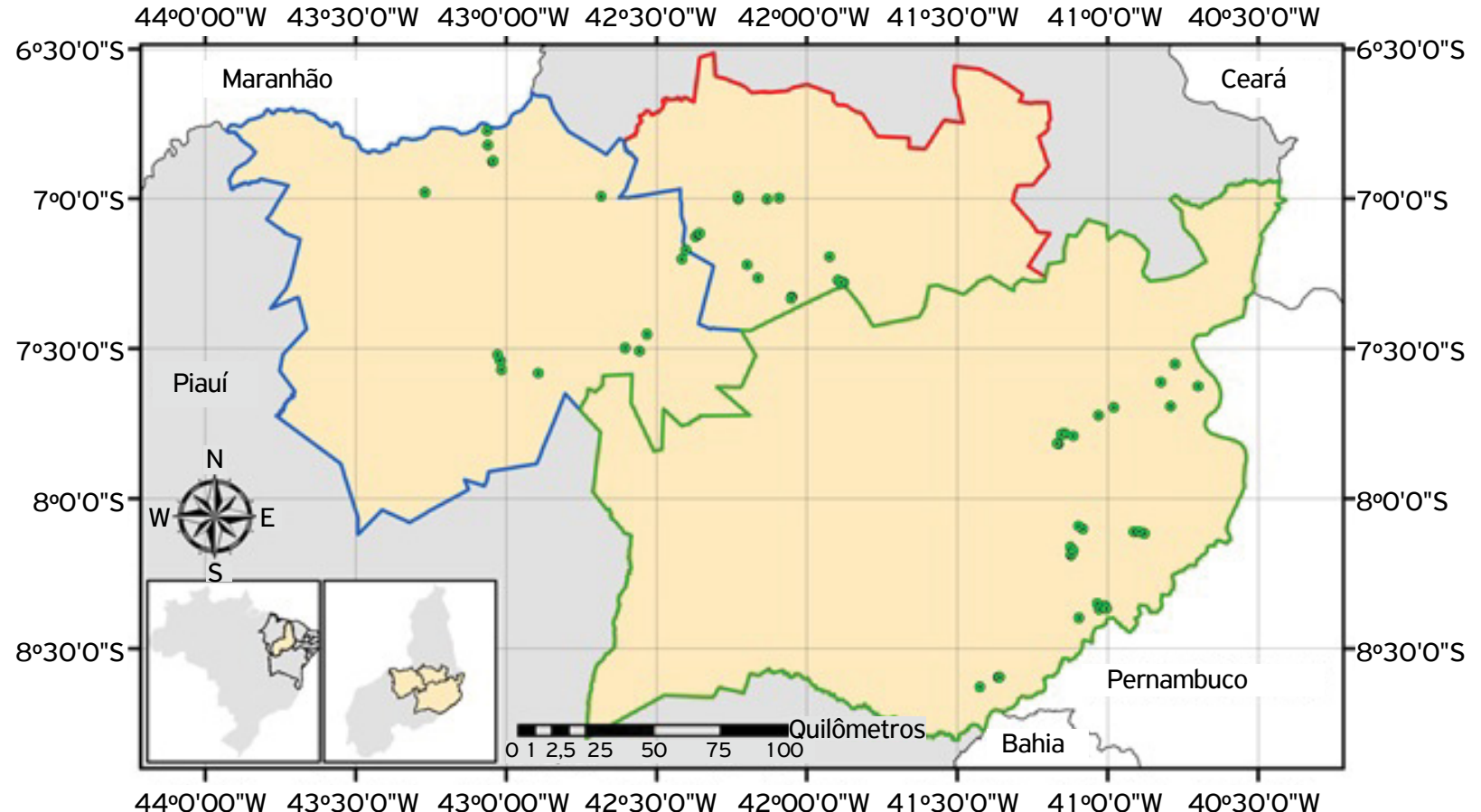

Figura 3. Localização georreferenciada das unidades produtoras de ovinos que participaram do estudo nas microrregiões do Alto Médio Canindé, Picos e Floriano, Piauí, Brasil. 
Bahia (SARDI et al., 2012) e São Paulo (ROSA et al., 2009) apontaram prevalências nulas do vírus na espécie ovina. Resultados demonstrando baixas prevalências foram constatados em outros estados nordestinos: 1,0\% em Pernambuco (COSTA et al., 2007), 0,5 e 0,3\% na Bahia (SOUZA et al., 2007; MARTINEZ et al., 2010) e 0,1\% em Sergipe (MENDONÇA et al., 2013). No Tocantins foi encontrado o resultado de $0,9 \%$ (SOBRINHO et al., 2008).
Evidências filogenéticas sugerem que a transmissão horizontal é particularmente a rota mais importante para a manutenção do vírus em rebanhos ovinos (BROUGHTONNEISWANGER et al., 2010), ocorrendo mais facilmente em situaçôes de altas densidades populacionais, pelo aumento da exposição a animais soropositivos e consequente contato com secreçôes contaminadas (BLACKLAWS et al., 2004; BROUGHTON-NEISWANGER et al., 2010;

Tabela 1. Distribuição da amostragem dos soros caprinos por município nas microrregiões do Alto Médio Canindé, Floriano e Picos, Piauí, Brasil.

\begin{tabular}{|c|c|c|c|c|}
\hline Microrregião & Município & Rebanho efetivo & Propriedades & Soros amostrados \\
\hline \multirow{7}{*}{ Alto Médio Canindé } & Queimada Nova & 25.568 & 7 & 140 \\
\hline & Capitão Gervásio Oliveira & 17.869 & 6 & 120 \\
\hline & Lagoa do Barro do Piauí & 17.774 & 5 & 100 \\
\hline & São Francisco de Assis do Piauí & 14.553 & 5 & 100 \\
\hline & São João do Piauí & 13.731 & 4 & 80 \\
\hline & Paulistana & 13.181 & 3 & 60 \\
\hline & Isaías Coelho & 11.572 & 2 & 40 \\
\hline \multirow{4}{*}{ Floriano } & São Francisco do Piauí & 10.069 & 6 & 120 \\
\hline & Itaueira & 9.095 & 4 & 80 \\
\hline & Floriano & 8.942 & 4 & 80 \\
\hline & São José do Peixe & 5.292 & 2 & 40 \\
\hline \multirow{3}{*}{ Picos } & Oeiras & 19.691 & 9 & 180 \\
\hline & Colônia do Piauí & 5.083 & 5 & 100 \\
\hline & Wall Ferraz & 3.468 & 2 & 40 \\
\hline Total & & 175.888 & 64 & 1.280 \\
\hline
\end{tabular}

Tabela 2. Distribuição da amostragem dos soros ovinos por município nas microrregiões do Alto Médio Canindé, Picos e Floriano, Piauí, Brasil.

\begin{tabular}{|c|c|c|c|c|}
\hline Microrregião & Município & Rebanho efetivo & Propriedades & Soros amostrados \\
\hline \multirow{7}{*}{ Alto Médio Canindé } & Jacobina do Piauí & 36.278 & 7 & 140 \\
\hline & Paulistana & 34.694 & 6 & 120 \\
\hline & Betânia do Piauí & 25.851 & 5 & 100 \\
\hline & Acauã & 25.090 & 5 & 100 \\
\hline & Simões & 24.217 & 4 & 80 \\
\hline & Queimada Nova & 22.658 & 3 & 60 \\
\hline & Caridade do Piauí & 17.052 & 2 & 40 \\
\hline \multirow{5}{*}{ Floriano } & Floriano & 13.329 & 6 & 120 \\
\hline & Itaueira & 8.610 & 4 & 80 \\
\hline & São José do Peixe & 8.591 & 4 & 80 \\
\hline & Nazaré do Piauí & 7.715 & 2 & 40 \\
\hline & São Francisco do Piauí & 6.525 & 2 & 40 \\
\hline \multirow{3}{*}{ Picos } & Oeiras & 14.626 & 8 & 160 \\
\hline & Colônia do Piauí & 5.570 & 4 & 80 \\
\hline & Wall Ferraz & 5.438 & 4 & 80 \\
\hline Total & & 256.244 & 66 & 1.320 \\
\hline
\end{tabular}


VILLORIA et al., 2013), podendo ainda ocorrer infecção pela inalação de aerossóis ou ingestão de água contendo partículas virais (VILLORIA et al., 2013).

Logo, rebanhos ovinocaprinícolas criados intensivamente são mais propensos a apresentarem altas prevalências da infecção pelo LV do que rebanhos submetidos a sistemas extensivos de criação. Mesmo que expostos ao vírus pela transmissão vertical, podem demonstrar prevalências baixas ou nulas (LEGINAGOIKOA et al., 2006). Essas informaçóes corroboram o resultado obtido neste trabalho, uma vez que não foi possível constatar sistemas intensivos de criação.

Este estudo é o primeiro levantamento soroepidemiológico realizado no estado do Piauí, no qual não foi possível detectar caprinos soropositivos. Entre as prevalências verificadas por outros pesquisadores em território piauiense, esse resultado aproxima-se do obtido por DINIZ (2011), na regiáo do sul piauiense, onde apenas $0,9 \%$ dos animais apresentaram anticorpos anti-LV. Porém, em pesquisas desenvolvidas na Regiáo Norte por PINHEIRO et al. (1996), BATISTA et al. (2004), SAMPAIO JUNIOR et al. (2011) e SILVA (2011) foram constatadas prevalências mais elevadas, de 4,4; 2,5; 3,9 e 4,1\%, respectivamente.

Os resultados encontrados aqui também se assemelham aos obtidos por SARDI et al. (2012) e por LIMA et al. (2013) em estudos feitos no semiárido baiano. Estes, ao pesquisarem anticorpos contra o LV em caprinos oriundos de rebanhos formados predominantemente por animais sem padrão racial definido (SPRD), utilizando a técnica de IDGA, constataram 0,0 e $0,2 \%$ de soroprevalência, nessa ordem.

Assim como observado na espécie ovina, a grande maioria dos caprinos que participaram desse estudo era nativa SPRD criada extensivamente, características que provavelmente influenciaram no resultado encontrado, já que práticas de manejo intensivo, mais comumente adotadas em criaçôes tecnificadas de raças com padrão genético elevado, como o confinamento e a utilização de tatuadores, aumentam o risco de transmissão horizontal (LARA et al., 2003).

A prevalência nula obtida na espécie caprina corrobora estudos que associam a ocorrência do LV a criaçóes de exploraçáo leiteira ou com animais de raça, em sistema intensivo (PINHEIRO et al., 2001; SILVA et al., 2005).

Em um levantamento sorológico realizado no estado do Ceará foi constatada soroprevalência nula em animais nativos SPRD (PINHEIRO et al., 2001). Já em animais mestiços e puros de raças leiteiras, foi possível identificar 0,1 e 4,6\% de soropositivos, respectivamente. A menor prevalência observada em animais mestiços foi atribuída por esses pesquisadores à prática frequente da utilização de apenas um reprodutor puro no rebanho, o que acaba restringindo a transmissão vertical.

$\mathrm{Na}$ espécie caprina, ressalta-se a alta ocorrência do LV em animais com predominância de raças leiteiras, por conta do estreito contato corporal, da utilização de ordenhadeiras mecânicas (BLACKLAWS et al., 2004; KONISHI et al., 2011), sala de maternidade, banco de colostro (SILVA et al., 2005) e amamentação coletiva dos cabritos (ÁLVAREZ et al., 2005), situaçóes que acabam propiciando a disseminação do vírus no rebanho. Porém, no presente trabalho, não se puderam encontrar nas microrregiôes estudadas rebanhos caprinos voltados à produção leiteira.

A IDGA utilizada nesta pesquisa detectou a proteína estrutural p28, que é a principal responsável pela formação da linha de precipitação do teste. Os resultados alcançados devem ser interpretados de forma cautelosa, pois é importante salientar que a probabilidade de ocorrência de falso-negativos é maior do que a de falso-positivos em decorrência da alta especificidade da técnica (OIE, 2008) e da sensibilidade menor quando comparada à de outros testes de triagem, como o ensaio imunoenzimático (ELISA) (BRINKHOF; VAN MAANEN, 2007). Entretanto, como se trata de análise de rebanhos, o teste apresenta bons resultados na detecção de soropositivos.

Esses resultados fornecem informaçōes fundamentais sobre a situação soroepidemiológica do LV em ovinos e caprinos nas microrregiōes estudadas e demonstram a importância da adoção de medidas preventivas contra esse agente infeccioso, uma vez que a predominância de sistemas de manejo extensivo e o indicativo da inexistência dessas enfermidades nos rebanhos pesquisados proporcionam condiçóes favoráveis para o controle e o monitoramento da condição sanitária das LVPR nas criaçóes de caprinos e ovinos das mesorregióes sudeste e sudoeste do estado do Piauí.

É importante enfatizar que, atualmente, para a emissão da Guia de Trânsito Animal (GTA) de pequenos ruminantes, a Agência de Defesa Agropecuária do Piauí (ADAPI) exige dos proprietários de caprinos, na impossibilidade da apresentação de resultado negativo ao teste de IDGA, apenas o atestado de sanidade, emitido por médico veterinário declarando que os animais não apresentam sinais clínicos da CAEV nos últimos 180 dias. Já para a obtenção de GTA da espécie ovina, não existe a obrigatoriedade de exame laboratorial com resultado negativo para LVPR, nem mesmo a apresentaçáo de atestado de sanidade que comprove a inexistência de sintomatologia clínica compatível com LVPR (PIAUÍ, 2007). Tal situação pode contribuir para a difusão dos $\mathrm{LV}$, tendo em vista que nem todos os animais infectados apresentam sinais clínicos (PETERHANS et al., 2004).

\section{CONCLUSÃO}

Nos rebanhos avaliados não foram encontrados animais sororreagentes ao LV, detectáveis pela técnica de IDGA. Entretanto, para confirmar a ausência do vírus nos rebanhos caprinos e ovinos dessas microrregiôes, torna-se necessária a realização de estudos com a utilização de técnicas diagnósticas mais sensíveis.

Em razão da significância da ovinocaprinocultura para as microrregióes estudadas, sugere-se a implantação de um rigoroso programa sanitário para que se possa evitar a introduçáo e/ou a disseminaçáo desses agentes infecciosos. 


\section{AGRADECIMENTOS}

Ao Conselho Nacional de Desenvolvimento Científico e Tecnológico $(\mathrm{CNPq})$ o financiamento da pesquisa por meio do edital CNPq/Ministério da Agricultura, Pecuária e Abastecimento (MAPA)/Secretaria de Defesa Agropecuária (SDA) n. ${ }^{\circ}$ 64/2008 e processo n. ${ }^{\circ}$ 578.438/2008-9; ao Centro
Nacional de Pesquisa de Caprinos e Ovinos da Empresa Brasileira de Pesquisa Agropecuária (EMBRAPA) o apoio técnico-financeiro, proporcionando a execuçáo deste trabalho; à Universidade Federal do Piauí (UFPI), ao Instituto de Assistência Técnica e Extensão Rural do Estado do Piauí (EMATER) e à Agência de Defesa Agropecuária do Piauí (ADAPI).

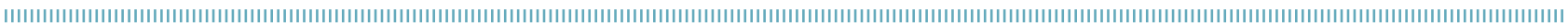
REFERÊNCIAS

ÁLVAREZ, V.; ARRANZ, J.; DALTABUIT-TEST, M.; LEGINAGOIKOA, I.; JUSTE, R.A.; AMORENA, B.; DE ANDRÉS, D.; LUJÁN, L.L.; BADIOLA, J.J.; BERRIATUA, E. Relative contribution of colostrum from Maedi-Visnavirus (MVV) infected ewesto MVV-seroprevalence in lambs. Research in Veterinary Science, v.78, n.3, p.237-243, 2005.

ALVES, F.S.F.; PINHEIRO, R.R. Presença da artrite encefalite caprina a vírus (CAEV) no estado do Maranhão. In: XXV CONGRESSO BRASILEIRO DE MEDICINA VETERINÁRIA, p. 278, 1997, Gramado. Anais... Gramado: Sociedade Brasileira de Medicina Veterinária, 1997.

ASTUDILLO, V.M. Encuestas por muestro para estúdios apidemiológicos em populaciones animales. Rio de Janeiro: Organización Panamericana de Fiebre Aftosa, 1979. 60p.

BANDEIRA, D.A.; CASTRO, R.S.; AZEVEDO, E.O.; MELO, L.S.S.; MELO, C.B. Seroprevalence of caprine arthritis-encephalitis virus in goats in the Cariri region, Paraiba state, Brazil. The Veterinary Journal, v.180, n.3, p.399-401, 2008.

BATISTA, M.C.S.; CASTRO, R.S.; CARVALHO, F.A.A.; CRUZ, M.S.P.; SILVA, S.M.M.S.; REGO, E.W.; LOPES, J.B. Anticorpos antilentivírus de pequenos ruminantes em caprinos integrantes de nove municípios piauienses. Ciência Veterinária dos Trópicos, v.7, n.2-3, p.75-81, 2004.

BLACKLAWS, B.A. Small ruminant lentiviruses: immunopathogenesis of visna-maedi and caprine arthritis and encephalitis virus. Comparative Immunology, Microbiology and Infectious Diseases, v.35, n.3, p.259-269, 2012.

BLACKLAWS, B.A.; BERRIATUA, E.; TORSTEINSDOTTIR, S.; WATT, N.J.; ANDRES, D.; KLEIN, D.; HARKISS, G.D. Transmission of small ruminant lentiviruses. Veterinary Microbiology, v.101, n.3, p. 199-208, 2004

BRASIL. Instituto Brasileiro de Geografia e Estatística - IBGE. Produção da Pecuária Municipal. Rio de Janeiro: IBGE, 2009. 55p.

BRASIL. Instituto Brasileiro de Geografia e Estatística - IBGE. Produção da Pecuária Municipal. Rio de Janeiro: IBGE, 2013. 108p.

BROUGHTON-NEISWANGER, L.E.; WHITE, S.N.; KNOWLES, D.P.; MOUSEL, M.R.; LEWIS, G.S.; HERNDON, D.R.; HERRMANNHOESING, L.M. Non-maternal transmission is the major mode of ovine lentivirus transmission in a ewe flock: a molecular epidemiology study. Infection, Genetics and Evolution, v.10, n.7, p.998-1007, 2010.
BRINKHOF, J.; VAN MAANEN, C. Evaluation of five enzyme-linked immunosorbent assays and an agar gel immunodiffusion test for detection of antibodies to small ruminant lentiviruses. Clinical and Vaccine Immunology, v. 14, n.7, p.1210-1214, 2007.

COSTA, L.S.P.; LIMA, P.P.; CALLADO, A.K.C.; NASCIMENTO, S.A.; CASTRO, R.S. Lentivírus de pequenos ruminantes em ovinos Santa Inês: isolamento, identificação pela PCR e inquérito sorológico no estado de Pernambuco. Arquivos do Instituto Biológico, v.74, n. 1, p.11-16, 2007.

DINIZ, B.L.M. Estudo zoosanitário da caprinocultura e da ovinocultura, e soroprevalência das lentiviroses de pequenos ruminantes na microrregião do alto médio gurguéia, na região sul do Piauí. 2011 . 179f. Tese (Doutorado em Ciência Animal) - Programa de Pós-Graduação em Ciência Animal da Universidade Federal do Piauí, Teresina, 2011.

GOUVEIA, A.M.G.; GUIMARAES, A.S.; HADDAD, J.P.A.; ABREU, C.P.; LEITE, R.C.; HEINEMANN, M.B.; LAGE, A.P.; CRUZ, J.C.M; CARMO, F.B. Características zoosanitárias da caprinocultura de corte em Minas Gerais, Brasil. Minas Gerais: Associação dos Criadores de Caprinos e Ovinos de Minas Gerais, 2009. 10p.

GOUVEIA, A.M.G.; MELO, L.M; PIRES, L.L.; PINHEIRO, R.R. Microimunodifusão em gel de ágar para o diagnóstico sorológico de infecção por lentivírus de pequenos ruminantes. In: CONGRESSO BRASILEIRO DE MEDICINA VETERINARIA, 27., Águas de Lindoia. Anais... Águas de Lindoia, 2000. p.33.

GOUVEIA, A.M.G.; LIMA, F.A.; ABREU, C.P.; LOBATO, Z.I.P.; YORINORI, E.H.; CYPRESTE, B.M. Lentiviroses de pequenos ruminantes em ovinos e caprinos em Minas Gerais. In: XI CONGRESSO LATINOAMERICANO, V CONGRESSO BRASILEIRO, III CONGRESSO NORDESTINO DE BUIATRIA, 2003, Salvador. Anais... 2003. p.52.

KONISHI, M.; NAGURA, Y.; TAKEI, N.; FUJITA, M.; HAYASHI, K.; TSUKIOKA, M.; YAMAMOTO, T.; KAMEYAMA, K.; SENTSUI, H.; MURAKAMI, K. Combined eradication strategy for CAE in dairy goat farm in Japan. Small Ruminant Research, v.99, n. 1, p.65-71, 2011.

LARA, M.C.C.S.H.; BIRGEL JÚNIOR, E.H.; FERNANDES, M.A.; BIRGEL, E.H. Infecção experimental do vírus da artrite-encefalite dos caprinos em cabritos. Arquivos do Instituto Biológico, v.70, n. 1, p.51-54, 2003.

LEGINAGOIKOA, I.; JUSTE, R.A.; BARANDIKA, J.; AMORENA, B.; DE ANDRES, D.; LUJAN, L.; BADIOLA, J.; BERRIATUA, E. Extensive rearing hinders maedi-visna virus (MVV) infection in sheep. Veterinay Research, v.37, n.6, p. 767-778, 2006. 
LIMA, C.C.V.; COSTA, J.N.; SOUZA, T.S.; MARTINEZ, P.M.; COSTA NETO, A.O.; AZEVEDO, D.A.A.; PINHEIRO, R.R.; BRITO, R.L.L. Imunodiagnóstico para a artrite-encefalite caprina em rebanhos do semiárido baiano, Brasil. Revista Brasileira de Medicina Veterinária, v.35, n.4, p.358-364, 2013.

MARTINEZ, P.M.; COSTA, J.N.; SOUZA, T.S.; COSTA NETO, A.O.; PINHEIRO, R.R. Sistemas de criação de ovinos e ocorrência de anticorpos contra o vírus da Maedi--Visna na Microrregião de Juazeiro - Bahia. Revista Brasileira de Saúde e Produção Animal, v. 11 , n.2, p.342-353, 2010.

MELO, C.B.; CASTRO, R.S.; OLIVEIRA, A.A.; FONTES, L.B.; CALLADO, A.K.C.; NASCIMENTO, S.A. Estudo preliminar sobre a infecção por lentivírus de pequenos ruminantes em ovinos e caprinos em Sergipe. In: CONGRESSO BRASILEIRO DE BUIATRIA, 5., Salvador. Anais... Salvador: Sociedade Brasileira de Buiatria, 2003. p.47-48.

MENDONÇA, C.E.D.; BARROS, S.L.B.; MENDONÇA, M.A.D.; GUIMARÃES, V.A.A.; PINHEIRO, R.R. Ocorrência de anticorpos contra o vírus Maedi-Visna em ovinos Santa Inês, no estado de Sergipe, Brasil. Arquivos Instituto Biológico, v.80, n.3, p.346-351, 2013.

MURRAY, P.; ROSENTHAL, K.S.; KOBAYASHI, G.S.; PFALLER, M.A. Retrovírus. In: MURRAY, P.; ROSENTHAL, K.S.; KOBAYASHI, G.S.; PFALLER, M.A. Microbiologia Médica. 3. ed. Rio de Janeiro: Guanabara Koogan, 2000. Cap. 61. p.422-433.

NARAYAN, O.; CLEMENTS, J.E. Biology and pathogenesis of lentiviruses. Journal of General Virology, v.70, n.7, p.16171639, 1989.

OIE - WORLD ORGANIZATION FOR ANIMAL HEALTH. Artritis/ encefalitiscaprina y Maedi-Visna. Manual de la OIE sobre animales terrestres 2008. 983p. Disponível em: < http://web. oie.int/esp/normes/mmanual/pdf_es_2008/2.07.03-04.\%20 Artritis-Encefalitis\%20caprina\%20y\%20Maedi\%20Visna. pdf>. Acesso em: 03 jan. 2015.

PETERHANS, E.; GREENLAND, T.; BADIOLA, J.; HARKISS, G.; BERTONI, G.; AMORENA, B.; ELIASZEWICZ, M.; JUSTE, R.; KRAßNIG, R.; LAFONT, J.; LENIHAN, P.; PÉTURSSON, G.; PRITCHARD, G.; THORLEY, J.; VITU, C.; MORNEX, J.; PÉPIN, M. Routes of transmission and consequences of small ruminant lentiviruses (SRLVs) infection and erradication schemes. Veterinary Research, v.35, n.3, p. 257-274, 2004.

PIAUÍ. Decreto n. 12.680 , de 18 de julho de 2007. Regulamenta a lei de defesa sanitária animal. Diário Oficial do Estado, Teresina, 18 jul. 2007.

PINHEIRO, R.R.; GOUVEIA, A.M.G.; ALVES, F.S. Prevalência da infecção pelo vírus da artrite encefalite caprina no estado do Ceará, Brasil. Revista do Centro de Ciências Rurais, v.31, n.3, p.449-454, 2001.

PINHEIRO, R.R.; ANDRIOLI, A.; GOUVEIA, A.M.G.; ARAGÃO, M.A.C.; MARTINEZ, P.M. Avaliação de antígenos para o diagnóstico de lentivírus em rebanho caprino sob programa de controle. Arquivos do Instituto Biológico, v.77, n.1, p.133-137, 2010.

PINHEIRO, R.R.; GOUVEIA, A.M.G.; ALVES, F.S.F.; ANDRIOLI, A. Perfil de propriedades no estado do Ceará relacionado à presença do lentivírus caprino. Ciência Animal, v. 14, n. 1, p.29-37, 2004.
PINHEIRO, R.R.; GOUVEIA, A.M.G.; ALVES, F.S.F.; HADDAD, J.P.A. Epidemiological aspects of the raising goat in Ceará state, Brazil. Arquivos Brasileiros de Medicina Veterinária e Zootecnia, v.52, n.5, p.534-543, 2000.

PINHEIRO, R.R.; ALVES, F.S.F.; GIRAO, E.S.; MEDEIROS, L.P.; GIRAO, R.N. Presença da artrite encefalite caprina a vírus (CAEV) em Teresina-PI. In: CONGRESSO BRASILEIRO DE MEDICINA VETERINÁRIA, 24., 1996, Goiânia. Anais... Goiânia: Sogove, 1996. p. 161.

REINA, R.; BERRIATUA, E.; LUJAN, L.; JUSTE, R.; SANCHEZ, A.; DE ANDRES, D.; AMORENA, B. Prevention strategies against small ruminant lentiviruses: an update. Veterinary Journal, v.182, n. 1, p.31-37, 2009.

ROSA, E.P.; AMORIM, R.M.; FERREIRA, D.O.L.; CHIACCHIO, S.B.; MODOLO, J.R. Soroprevalência da pneumonia progressiva ovina Maedi-Visna na região de Botucatu, SP. Ciência Animal Brasileira, v.10, n.3, p.847-852, 2009.

SAMPAIO JÚNIOR, A.; BATISTA, M.C.S.; CRUZ, M.S.P.; SILVA, R.A.B.; BONA NASCIMENTO, C.; WERNECK, G.L. Prevalência da infecção por lentivírus de pequenos ruminantes em caprinos em Teresina, Piauí. Arquivo Brasileiro de Medicina Veterinária e Zootecnia, v.63, n.3, p.757-760, 2011.

SARDI, S.I.; TORRES, J.A.; BRANDÃO, C.F.L.; TIGRE, D.M.; CAMPOS, G.S. Early detection of goats infected with lentivirus small ruminant virus by ELISA assay. Revista de Ciências Médicas e Biológicas, v. 11 , n. 1, p.35-40, 2012.

SHAH, C.; BONI, J.; HUDER, J.B.; VOGT, H.R.; MUHLHERR, J.; ZANONI, R.; MISEREZ, R.; LUTZ, H.; SCHUPBACH, J. Phylogenetic analysis and reclassification of caprine and ovine lentiviruses based on 104 new isolates: evidence for regular sheep-to-goat transmission and world propagation through livestock trade. Virology, v.319, n.1, p.12-26, 2004.

SILVA, J.S.; CASTRO, R.S.; MELO, C.B.; FEIJÓ, F.M.C. Infecção pelo vírus da artrite encefalite caprina no Rio Grande do Norte. Arquivo Brasileiro de Medicina Veterinária e Zootecnia, v.57, p.726-731, 2005.

SILVA, R.A.B. Caracterização epidemiológica das lentiviroses de pequenos ruminantes na microrregião homogênea de Teresina, Piauí. 201 1. 90f. Dissertação (Mestrado em Ciência Animal) Programa de Pós-Graduação em Ciência Animal da Universidade Federal do Piauí, Teresina, 2011.

SOBRINHO, P.A.M.; FERNANDES, C.H.C.; RAMOS, T.R.R.; CAMPOS, A.C.; COSTA, L.M.; CASTRO, R.S. Prevalência e fatores associados à infecção por lentivírus de pequenos ruminantes em ovinos no estado do Tocantins. Ciência Veterinária nos Trópicos, v.11, n.2/3, p.65-72, 2008.

SOUZA, T.S.; COSTA, J.N.; MARTINEZ, P.M.; PINHEIRO, R.R. Estudo sorológico da Maedi-Visna pelo método da imunodifusão em gel de ágar em rebanhos ovinos de Juazeiro, Bahia, Brasil. Revista Brasileira de Saúde e Produção Animal, v.8, n.4, p.276-282, 2007.

VILLORIA, M.; LEGINAGOIKOA, I.; LUJÁN, L.; PÉREZ, M.; SALAZAR, E.; BERRIATUA, E.; JUSTE, R.A.; MINGUIJÓN, E. Detection of small ruminant lentivirus in environmental samples of air and water. Small Ruminant Research, v.110, n.2-3, p.155-160, 2013. 